\title{
O acolhimento no processo de trabalho em saúde ${ }^{1}$
}

\author{
The user embracement in the process of health work
}

\author{
Sabrina Alves Ribeiro Barra *
}

\begin{abstract}
Resumo:
Este artigo é uma revisão bibliográfica subsidiada pelo entendimento de que no campo do trabalho em saúde, o acolhimento se mostra como uma tecnologia fundamental na busca pela integralidade da assistência. Por meio da escuta e do diálogo, permite a humanização da relação profissional-usuário, a decodificação das necessidades de saúde e, a construção de processos de vínculo e trabalho em equipe. $\mathrm{O}$ artigo apresenta uma discussão sobre o processo de trabalho em saúde no campo da micropolítica, considerando sua relação com a gerência e gestão da política de saúde, bem como a conjuntura social, política, econômica e cultural em que se inserem. Posteriormente apresenta-se uma reflexão sobre o cuidado e a humanização em saúde, destacando o acolhimento como uma possibilidade para se construir um modelo de atenção à saúde centrado no usuário, com foco na saúde e não na doença.
\end{abstract}

Palavras chave: Trabalho em saúde. Humanização. Acolhimento.

\begin{abstract}
:
The user embracement in the process of health work. This article is a literature review aided by the understanding that the field of health work, the user embracement appears as a essential technology in the quest for integrality care. Through listening and dialogue, allows the humanization of the professional-user relationship, the decoding of health needs, and building of bonding and teamwork. This article presents a discussion about the process of health work in the field of micropolitics, considering its relationship with management and management of health policy and the social, political, economic and cultural environment in which they operate. Then, presents a reflection on the care and humanization health, highlighting the user embracement as an opportunity to build a model of care health user-centric, focusing on health and not disease.
\end{abstract}

Keywords: Healthcare work. Humanization of assistance. User embracement.

\footnotetext{
${ }^{1} \mathrm{O}$ conteúdo deste artigo é parte integrante da monografia apresentada ao Curso de Especialização em Políticas e Pesquisa em Saúde Coletiva/UFJF no ano de 2011, com o título - Acolhimento na Atenção Primária à Saúde: dispositivo disparador de mudanças na organização do processo de trabalho? - sob a orientação da Professora Doutora Lêda Maria Leal de Oliveira.

*Faculdade de Serviço Social -Universidade Federal de Juiz de Fora - sassabarra@yahoo.com.br
} 


\section{O processo de trabalho no campo da saúde}

O trabalho em saúde surge a partir do momento em que o homem começa a buscar respostas para as suas necessidades de saúde, ou seja, quando começa a se perguntar sobre seu adoecimento e as formas de resolvê-lo, criando um tipo específico de trabalho para satisfazer tais necessidades (LIMA, 2007).

Este trabalho situa-se no âmbito da esfera não material, fazendo parte do setor de serviços. A finalidade do trabalho em saúde é uma ação terapêutica, entendida como ações de cura, reabilitação, prevenção e promoção da saúde. O objeto são os próprios indivíduos ou grupos doentes ou não, ou expostos a riscos de adoecer e que necessitam de tais ações. Os meios para a realização do trabalho são os instrumentos e o conhecimento técnico, materializados nas condutas de cada profissional. O produto final é a própria prestação da assistência à saúde que é consumida no momento exato de sua produção (FRIEDERICH, 2005).

O trabalho em saúde é realizado em diversos espaços como Unidades de saúde, hospitais, ambulatórios e assume características particulares em cada um deles, mas mantendo sempre o mesmo objeto, finalidade e produto final. É um trabalho realizado por um coletivo de trabalhadores que se inserem direta ou indiretamente no processo produtivo, como as 14 profissões definidas pelo Conselho Nacional de Saúde (CNS), os profissionais de nível técnico e os motoristas, serviços gerais, porteiros que de alguma forma participam na prestação dos serviços.

A presença de diferentes categorias profissionais expressa a existência de diversos núcleos de saberes específicos em inter-relação, já que para alcançar a finalidade do trabalho em saúde é necessário a integração de saberes que deem conta dos múltiplos fatores sociais, culturais, biológicos e econômicos que interferem no processo de saúde/doença.

As ações produzidas no campo da saúde são, então, expressões de diversos conhecimentos específicos de cada profissional comprometidos com o mesmo objetivo de produzir atos que respondam às necessidades de saúde. De acordo com Abrahão (2007), estes atos são produzidos nos espaços intercessores, entendidos como momentos de encontro entre trabalhadores da saúde e destes com os usuários. São momentos de mediação entre saberes operados e de produção de ações de saúde. 
O processo de trabalho em saúde nos revela a presença de diferentes elementos materiais e não materiais empregados na produção dos atos de saúde. Esses elementos podem ser traduzidos como as tecnologias de saúde utilizadas em cada caso. Merhy $(1997,2002)$ define tecnologia como um conjunto de conhecimentos e modos de agir aplicados à produção de algo.

As tecnologias podem ser expressas em: conhecimentos materializados nas máquinas e equipamentos constituindo as tecnologias duras; saberes estruturados que conformam o conhecimento adquirido pelos profissionais por meio de sua formação e experiência de trabalho, representando as tecnologias leve-duras e; relações presentes na produção dos atos de saúde: modos de produzir acolhimento, vínculo e responsabilização que são as tecnologias leves, as tecnologias das relações.

O uso destas tecnologias se dá de forma articulada durante todo o processo de trabalho. Cada profissional guarda um conjunto tecnológico e o utiliza em cada situação singular de acordo com a necessidade do seu emprego no cuidado em saúde (ABRAHÃO, 2007).

De acordo com a referida autora, no cuidado em saúde, os trabalhadores operam esses núcleos tecnológicos que contêm trabalho morto e trabalho vivo, com a centralidade deste último. De acordo com Merhy (2002), o trabalho morto é entendido como a cristalização de um trabalho humano anterior, expresso em ferramentas ou matéria-prima. É resultado do trabalho vivo, que é o trabalho em si, no ato de sua produção. O trabalho vivo em ato é o trabalho criador, e o trabalho morto já está instituído.

O modo como o processo de trabalho se organiza pode revelar a hegemonia do trabalho morto, quando o modelo assistencial se caracteriza pelo modelo curativista, centrado em procedimentos médicos e de alta densidade tecnológica. Quando ocorre o predomínio do trabalho vivo, há uma mudança no modelo assistencial que passa a se caracterizar pela produção de cuidados multidisciplinares centrados nas necessidades dos usuários (ABRAHÃO, 2007).

A centralidade do trabalho vivo em ato na saúde deve ocorrer justamente porque neste setor o trabalho é essencialmente relacional e atua sobre sujeitos e não sobre 
objetos inertes. Produção e consumo dos atos de saúde ocorrem no mesmo momento nos espaços intercessores onde as tecnologias leves devem ser a dimensão-chave.

O trabalho vivo em ato permite em certa medida, o exercício da criatividade e liberdade do trabalhador. Merhy (2002) aponta uma importante característica do trabalho em saúde que é o autogoverno, a autonomia dos trabalhadores nas relações que se estabelecem entre os sujeitos envolvidos no processo de trabalho. O autogoverno representa a capacidade de o trabalhador organizar seu processo de trabalho, aplicar suas tecnologias, definir o modo como estabelecerá suas relações com os usuários e com os membros da equipe.

O autor considera que o processo de trabalho em saúde não ocorre de modo idêntico ao do mundo produtivo das fábricas, uma vez que as ações em saúde são menos normatizadas e ocorrem por meio da relação entre trabalhador e usuário, potencializando o trabalho vivo. Por isso, para o autor o trabalho em saúde não pode ser totalmente capturado pelo trabalho morto, pautando-se somente no uso das tecnologias duras, pois "o jogo produção, consumo e necessidades tem uma dinâmica muito peculiar, que faz com que esteja sempre em estruturação, dentro de um quadro permanentemente incerto, sobre o padrão do seu produto final e o modo de satisfação que o mesmo gera" (MERHY, 2002, p. 98). A potência instituinte do trabalho vivo em ato permite o uso das tecnologias leves e a busca pelas "linhas de fuga" para os "ruídos" do processo de trabalho. Isto quer dizer que o autogoverno dos trabalhadores da saúde os permite construir estratégias paras os entraves, as dificuldades encontradas no processo de trabalho fugindo a uma lógica normativa.

Ao mesmo tempo, a organização do processo de trabalho deve ser entendida na sua historicidade e na articulação com a totalidade social da qual emerge e faz parte (LIMA, 2007). De acordo com Campos (1997), não é possível definir um sujeito a partir dele mesmo, pois os indivíduos, os agrupamentos e as classes sociais se constituem pela rede de relações na qual estão imersos. Os trabalhadores da saúde são produtos e produtores do sistema de relações da sociedade atual em seu contexto sócio-histórico.

Como produtos, os trabalhadores sofrem influência das políticas governamentais, do saber estruturado em disciplinas, das leis e valores culturais de cada época. Como produtores participam da construção de saberes, influenciam as políticas, constroem o 
Sistema de Saúde, interagem com a sociedade exercendo relativo grau de autonomia, apesar dos determinantes externos ao seu trabalho.

O autor, ao analisar a relação entre autonomia dos trabalhadores da saúde e a gerência e gestão dos processos de trabalho, aponta que para assegurar a qualidade e a eficácia em saúde seria necessário combinar graus adequados de autonomia profissional com definição de responsabilidades e compromissos, sem inibir e/ou aprisionar a iniciativa dos trabalhadores.

Para o autor, a adequada combinação entre autonomia profissional e controle institucional se expressa pelo cumprimento de três critérios: a capacidade de produzir saúde de um serviço, a viabilidade técnica, política e financeira deste e a realização profissional e financeira dos trabalhadores. Ou seja, o interesse dos usuários, dos trabalhadores e a viabilidade devem estar articulados de modo que se alcance ao mesmo tempo a máxima realização possível de cada um.

Nesse contexto, a gestão e a gerência do trabalho em saúde exercem papel fundamental ao buscar os meios para a garantia do cumprimento destes critérios. Devem estimular, a partir da viabilidade e da realização profissional, a promoção de processos de trabalho centrados no usuário e no uso de tecnologias leves para que o trabalhador possa desempenhar o ato cuidador e atender ao interesse dos usuários. De outro modo, se a gerência impulsiona processos de trabalho altamente normatizados faz com que o profissional perca o ideal da promoção da saúde, e o seu trabalho passa a ser exercido de forma automática e rígida, apenas para alcançar resultados e cumprir metas (ABRAHÃO, 2007). Perde-se a dimensão cuidadora do trabalho em saúde tanto para usuários quanto para profissionais.

De acordo com Schraiber et al. (1999), o papel da gestão do trabalho em saúde é de grande complexidade, visto que deve articular a garantia da universalidade e equidade na prestação de serviços; possibilitar a participação popular e profissional nos processos decisórios no que tange à organização da produção e também na execução dos cuidados em saúde; trabalhar com foco na integralidade das ações, estimulando a interação no trabalho cotidiano e gerenciando conflitos; ao mesmo tempo em que deve encontrar a melhor forma de obter alta resolutividade e boa qualidade das ações que serão produzidas. 
Para as autoras, a avaliação e o controle da qualidade dessas ações devem ser definidas entre os profissionais e gestores tornando-se um mecanismo de resgate do diálogo, da verticalização das ações, com vistas à profissionalização, ao orgulho, e à valorização do trabalho. Essa integração permite o exercício do trabalho vivo em ato, ao buscar a capacidade criativa e criadora do profissional da saúde que passará a refletir sobre o desenvolvimento do seu próprio trabalho e do processo de trabalho como um todo, buscando estratégias para qualificação do cuidado.

Nesta relação entre o desenvolvimento do trabalho e os processos de gestão deste, Pierantoni (2001), apresenta alguns princípios básicos da administração que devem ser reconhecidos e aplicados na gestão em saúde. O primeiro deles se refere ao reconhecimento do papel central dos profissionais na vida da instituição. Esse reconhecimento implica assumir e efetivar a prática de mecanismos participativos de gestão.

O segundo princípio se expressa pela incorporação da responsabilidade com os objetivos e as práticas institucionais, substituindo mecanismos de controle de desempenho de atividades por espaços que favoreçam a criatividade e iniciativa do trabalhador. E o terceiro princípio refere-se à utilização do espaço de gestão também para controle de interesses individuais e corporativistas, em defesa dos interesses da coletividade e do alcance da qualificação da assistência.

A adoção destes três princípios básicos permite a organização democrática do trabalho com foco nas necessidades do usuário e na integração entre os atores envolvidos na produção do cuidado, usuários, trabalhadores e gestores.

Discutindo sobre essa integração no que se refere à relação entre os trabalhadores da saúde, Ribeiro, Pires e Blank (2007) argumentam que o trabalho coletivo em saúde, apesar de direcionar-se para o mesmo objeto que são os seres humanos com suas necessidades de saúde, desenvolve-se de forma individualizada, cada profissional se organiza para prestar parte da assistência de saúde, acarretando muitas vezes, duplicação de ações e até mesmo atitudes contraditórias. Quando ocorre esse distanciamento do produto final do trabalho em saúde, este aproxima-se da divisão técnica ou parcelar do trabalho, ficando submetido às decisões gerenciais. 
Por outro lado, as autoras apontam que quando há um envolvimento e um domínio de todos os profissionais sobre o processo de trabalho, este aproxima-se do trabalho do tipo profissional, entendido como um trabalho em que os trabalhadores possuem relativa autonomia sobre os ritmos, processos e produtos de sua ação. Logo, quanto maior o domínio sobre o processo de trabalho, mais próximo está do trabalho do tipo profissional e quanto menor esse domínio maior é a aproximação com o trabalho parcelar.

A organização parcelar do trabalho em saúde, fazendo com que cada profissional participe apenas de uma etapa do projeto terapêutico, produz alienação. Campos (1997, p. 234) argumenta que:

\footnotetext{
Na verdade, se o profissional não se sente sujeito ativo no processo de reabilitação ou na trajetória de invenção de programas para debelar um problema sanitário mais coletivo, ele não somente perderá contato com elementos potencialmente estimuladores de sua criatividade, como tenderá a não se responsabilizar pelo objetivo final da própria intervenção, ou seja, pela recuperação do paciente ou pela promoção da saúde de uma comunidade.
}

Em consequência os profissionais se preocupam com a realização de ações pontuais e isoladas, perdendo a perspectiva de um cuidado ampliado com integração da equipe de trabalho. Os resultados dessas ações se perdem no processo de trabalho e os profissionais perdem o contato com o resultado final de sua ação.

O autor ressalta ainda que essa alienação prejudica tanto o usuário quanto os próprios trabalhadores. A divisão do conhecimento em fragmentos do processo de trabalho "não somente embrutece o profissional, como o aborrece" (CAMPOS, 1997, p. 235), ao concentrar-se em ações esvaziadas de sentido, ou ações que dependem de uma continuação que o profissional não domina e muitas vezes, até desconhece. Em consequência constrói-se um saber e prática profissionais muito burocratizados e mecanizados que afastam cada profissional do resultado de sua "Obra", que o autor entende como o reconhecimento por parte de trabalhadores, usuários e da sociedade como um todo do resultado do seu trabalho.

De acordo com Friederich (2005) a organização e a divisão do trabalho ocorrem de acordo com o objetivo final que se busca atingir. Se o objetivo é a produção da cura, com base na concepção médico-curativa, o processo de trabalho é fragmentado, com cada 
profissional prestando parte da assistência. Se o objetivo final é a produção de saúde, centrada na concepção do cuidado, o processo de trabalho enfatiza o trabalho em equipe, a humanização da assistência e a responsabilidade e resolutividade.

No primeiro caso, o trabalho concentra-se na atuação do médico, e de tecnologias duras. Os demais profissionais, apesar de suas especificidades, acabam por atuar em atividades complementares ao ato médico. Já no segundo caso que é a produção da saúde, o trabalho é desenvolvido em equipe, e há predomínio no uso das tecnologias leves.

\section{Cuidar: a essência do processo de trabalho em saúde}

O trabalho em saúde pode ser compreendido como ações humanas destinadas ao cuidado com o outro, na medida em que demanda uma relação subjetiva e dialógica no encontro entre profissionais de saúde e usuários, na busca pelo atendimento às necessidades de saúde. Silva Júnior et al. (2005) entendem que o cuidado no campo da saúde é a sua própria razão de ser, constituindo-se como meio e fim das ações desenvolvidas.

Para os autores, a idéia de cuidado em saúde foge ao desenvolvimento de ações pontuais e isoladas, e se configura nos encontros entre sujeitos como uma interação que possibilita o acesso às alternativas de solução para as necessidades de saúde. Essa interação implica construção de vínculos e responsabilizações mútuas, ancoradas na perspectiva da integralidade enquanto um princípio do SUS.

A integralidade pode ser entendida como um valor que deve nortear as ações de saúde. Está relacionada ao desenvolvimento de ações de promoção, prevenção e cura, bem como à consideração do indivíduo para o qual se destinam aquelas ações, como um sujeito em seu contexto socioeconômico e cultural onde suas demandas de saúde ganham significados. Tomando por base esse princípio a atenção em saúde só pode ocorrer por meio de relações de cuidado.

Discutindo sobre o cuidado nas práticas de saúde, Ayres (2006) aponta que o cuidado é uma sabedoria prática relacionada aos saberes tecnocientíficos que se concretiza mediante ações instrumentais subordinadas ás escolhas compartilhadas na relação entre profissionais de saúde e usuários. O objetivo é construir uma relação 
horizontal, na qual os sujeitos envolvidos buscam juntamente as respostas para os problemas encontrados e na qual as concepções e intenções do usuário também são consideradas na busca pelo alcance de seus projetos de vida.

Nesse entendimento, o cuidado transcende a técnica e a ciência, configurando-se como um saber que não cria apenas objetos, mas constitui sujeitos, na medida em que considera e valoriza o saber do outro e sua participação nas práticas de saúde. Para o autor, é aqui que a dimensão do cuidar ganha destaque por meio dessa sabedoria prática para a saúde que se apoia na tecnologia, mas não se resume a ela, se constrói cotidianamente nos serviços de saúde.

A dimensão do cuidado para se concretizar no cotidiano do trabalho em saúde necessita de condições estruturais dentro da instituição em que se realiza como depende também do direcionamento mais geral da política de saúde. Isto quer dizer que para que um profissional possa exercer o cuidado, ele necessita de boas condições de trabalho, de equipamentos e insumos necessários em cada caso, o que dependerá dos valores que orientam a condução das políticas de saúde no âmbito da gestão.

É na busca da dimensão do cuidado nas práticas de saúde em relação aos aspectos macroestruturais que interferem neste, que podemos destacar a Política Nacional de Humanização (PNH). Esta lança a humanização como eixo norteador das práticas de atenção e gestão da saúde em todas as instâncias do SUS, como um meio para alcançar o cuidado em saúde. Busca orientar a produção de um novo tipo de interação entre os sujeitos que constituem os sistemas de saúde, qualificando a atenção e a gestão em saúde, em sintonia com um projeto de corresponsabilidade e construção de vínculos (BRASIL, 2004).

O discurso oficial da humanização no contexto do SUS explicita princípios como: a valorização dos sujeitos implicados na produção da saúde - usuários, trabalhadores e gestores; incentivo à autonomia e protagonismo; co-responsabilidade na atenção e gestão em saúde; identificação de necessidades sociais; construção de vínculos; fortalecimento do trabalho em equipe; compromisso com a qualidade do ambiente, das condições de trabalho e atendimento. A humanização associa-se à qualidade técnica e ética do cuidado, reconhecendo os direitos do usuário e valorizando os profissionais (TRAD, 2006). 
Podemos dizer que o ideal de humanização das práticas de saúde tem como premissa básica a construção de uma atenção centrada no usuário, reconhecendo este como um cidadão que usa os serviços de saúde como um direito social. Em consequência desse reconhecimento vêm todas as outras questões relacionadas à humanização, desde o plano da micropolítica até a macroestrutura do sistema de saúde.

A humanização pode ser vista como uma política transversal que perpassa todos os programas e serviços do sistema de saúde, buscando oferecer atendimento de qualidade pela combinação entre avanços tecnológicos e bom relacionamento baseados na comunicação como premissa básica para o cuidado em saúde (ARTIMANN; RIVERA, 2006).

Trad (2006) apresenta dois eixos da humanização: o uso das tecnologias leves, como o acolhimento, o vínculo e a autonomia e, o reconhecimento das necessidades do usuário, dotando-as de significados de acordo com o contexto em que elas se inserem, considerando que a construção destas é social e historicamente determinada e que o processo saúde/ doença tem sua gênese nas condições materiais de vida (RAMOS, 2007).

Humanização e cuidado em saúde incluem então, a compreensão e reflexão sobre as necessidades de saúde e sobre as formas ampliadas de intervir sobre estas. Tal compreensão de necessidades de saúde associa-se diretamente ao conceito ampliado de saúde, em que a "situação sócio-econômica, as identidades de gênero, etnia ou de raça condicionam o desenvolvimento das capacidades de cada pessoa" (STOTZ, 2003, p. 1).

Discutindo sobre os conceitos e representações de tais necessidades de saúde, Cecílio (2001) aponta que estas podem ser englobadas em quatro conjuntos.

O primeiro se refere a ter boas condições de vida, no entendimento de que os diferentes lugares ocupados pelos indivíduos no processo de produção da sociedade capitalista resultam em diferentes modos de adoecer. Os modos/ hábitos de vida, condições de trabalho e moradia, acesso a lazer, educação etc traduzem diferentes necessidades de saúde.

O segundo conjunto de necessidades se refere ao acesso a serviços de saúde e às tecnologias de saúde que podem contribuir para melhorar e prolongar a vida. O uso dessas tecnologias, independente de sua densidade, é sempre definido pela necessidade de cada pessoa em cada momento singular. 
O terceiro conjunto diz respeito à criação de vínculos entre usuários e profissionais, enquanto relações de confiança contínuas que contribuem para a eficácia das ações de saúde e permitem ao usuário a identificação com o Sistema de Saúde.

O quarto conjunto está associado à construção de autonomia dos usuários, incluindo a busca pela satisfação de suas necessidades. Nesse processo, a informação e a educação em saúde se constituem importantes ferramentas para as equipes de saúde na busca pela construção dessa autonomia.

O autor argumenta ainda que as necessidades de saúde são travestidas em demandas específicas e muitas vezes modeladas pela oferta dos serviços de saúde. Cabe aos profissionais a sensibilidade para decodificar e saber intervir da melhor maneira possível, o que só é possível por meio de uma escuta qualificada.

$\mathrm{Na}$ mesma perspectiva, Ramos (2007) aponta que a intervenção sob as necessidades de saúde, consideradas nessa perspectiva ampliada, implica ações que incidam nos determinantes do processo saúde/doença e não apenas na doença em si, rompendo com o caráter curativo da assistência. O autor aponta que há uma tendência predominante que associa necessidades de saúde ao consumo de um serviço de saúde, geralmente uma consulta médica, modelando a necessidade do usuário ao que o serviço pode ofertar.

Para Stotz (2003), organizar um sistema de saúde pautado em uma visão ampliada de necessidades, buscando a resolutividade e a integralidade da assistência, significa construir um modelo de proteção à saúde em que além de se considerar os diversos fatores e atores envolvidos no processo saúde/doença, busca-se uma diversidade de projetos terapêuticos que atendam a essas necessidades.

Assim, humanizar a assistência buscando o cuidado em saúde significa o reconhecimento das necessidades de saúde e o uso de tecnologias leves, que permitam o estabelecimento de relações dialógicas intraequipe e desta com os usuários em toda a rede de saúde. Significa o compromisso em acolher as demandas dos usuários construindo vínculos e processos de autonomia e corresponsabilização.

O reconhecimento e a valorização da dimensão dialógica nos atos de cuidar significam a abertura a um interesse em "ouvir o outro" rompendo com o monólogo característico da tecnociência. Poder ouvir e fazer-se ouvir são a essência de um diálogo 
que quer alcançar o cuidado em saúde. O que se destaca é a qualidade da escuta que busca ir além das demandas explícitas, que correlaciona o contexto do usuário e fornece a este condições de refletir sobre seu próprio modo de vida. Um dispositivo que se destaca nessa dimensão é o acolhimento, enquanto uma tecnologia leve que propicia tal interação (AYRES, 2006).

O diálogo permite a construção de vínculos e de confiança na relação usuárioprofissional, contribuindo para o estabelecimento de compromissos e responsabilidades. Para Ayres (2006), a responsabilidade também assume relevância no cuidado em saúde, desde as relações no plano da micropolítica do trabalho em saúde até o plano da gestão dos serviços que também deve estar comprometida com a construção do cuidado.

Considerando os processos de autonomia do trabalho em saúde, tanto entre trabalhadores quanto entre usuários, podemos entender a responsabilização como uma corresponsabilização em que todos se comprometem e participam das práticas de saúde. O usuário também se torna responsável pelo atendimento às suas necessidades, mediante relações usuário-serviço.

Tais questões são fundamentais para a construção do cuidado e remetem à importância do trabalho em equipe, pois a eficácia do trabalho em saúde depende da composição e cooperação de diferentes saberes e técnicas que juntos deem conta de responder às necessidades de saúde. Há uma interdependência no trabalho em saúde, devido aos diversos fatores (biológicos, sociais, culturais etc) que interferem no processo saúde/doença, demandando uma atuação interdisciplinar.

A ideia de equipe de saúde, de acordo com Peduzzi (2003), não se refere somente a uma justaposição de profissionais, mas sim à integração e articulação de diferentes processos de trabalho, considerando que cada trabalho especializado possui saberes, instrumentos e objetivos próprios. Essa integração, por sua vez, não quer dizer eliminação das diferenças que também são necessárias e podem contribuir para o avanço da democratização e da ética nas relações de trabalho e no próprio trabalho produzido. A superioridade do trabalho em equipe não exclui a necessidade de definição clara e precisa das responsabilidades individuais diante de cada caso.

A autora aponta que a interdependência do trabalho em saúde tenciona a necessidade de cooperação dos trabalhos e a necessidade de autonomia técnica. Ao 
mesmo tempo em que o profissional necessita de liberdade para tomar decisões e em algumas situações isolamento para implementá-las, não pode prescindir do trabalho de outros profissionais. Justamente por ser especializado não domina a integralidade do projeto de trabalho.

De modo semelhante Ramos (2007), aponta que nenhum trabalhador é sujeito pleno da totalidade do processo de trabalho e que a superação da atual fragmentação deste implica que todos os envolvidos se apropriem, no plano da consciência e da materialidade das relações de produção, dos objetivos e razões do trabalho em saúde.

Alguns dispositivos podem ser utilizados para construção do trabalho em equipe, como as discussões de casos, as reuniões interdisciplinares, a educação permanente e avaliação sistemática do processo de trabalho (SILVA JÚNIOR et al, 2005). Essa integração para Schraiber et al (1999) pressupõe o compartilhamento de informações produzidas e registradas entre os profissionais envolvidos no processo de trabalho. As autoras discutem ainda que esta integração refere-se tanto aos produtores diretos do serviço quanto aos gestores destes em uma perspectiva articuladora dos trabalhos em um projeto comum.

O trabalho em equipe também pode ser associado à construção de redes nos serviços e no Sistema de Saúde como um todo, conforme define Franco (2006). A ideia é que as relações entre os profissionais sejam horizontais e formem redes de trabalho em equipe, tendo como centro da produção do cuidado o usuário, fugindo de uma organização da assistência rígida, normatizada, burocratizada e fragmentada. As redes simbolizam as comunicações entre todos os atores envolvidos no cuidado em saúde e são expressas pelas relações de acolhimento, vinculo, trabalho em equipe e corresponsabilizações.

Os usos destas tecnologias de cuidado nos processos de trabalho definem um perfil da assistência usuário-centrado. Para Franco e Merhy (2005), é possível construir esse novo processo de trabalho superando a lógica atual de centrar as ações em procedimentos isolados. Esta lógica, para os autores, acaba por contribuir para a "construção imaginária da demanda" por meio da qual os usuários identificam que a resposta para as suas necessidades de saúde está nas ações técnicas e nos 
procedimentos. A aposta nas tecnologias leves, tendo por base a integralidade do cuidado e a humanização da assistência, é que pode contribuir para essa mudança.

Dentre as tecnologias leves, destaco o acolhimento como um dispositivo capaz de qualificar as relações intraequipe e entre profissionais e usuários, reorganizar o processo de trabalho e efetivar os princípios e diretrizes do SUS.

\section{O acolhimento como uma ferramenta para organizar o processo de trabalho em}

\section{saúde de modo usuário-centrado}

As ações de saúde são produzidas em encontros entre trabalhadores de saúde e usuários, em que processos tecnológicos são operados por meio de relações de escutas, responsabilizações e vínculos com objetivo de responder às necessidades de saúde (FRANCO; BUENO; MERHY, 1999). É nessa relação que o acolhimento apresenta-se como uma ferramenta capaz de qualificar a prestação da assistência ao centrar a organização do processo de trabalho no usuário, e ao considerá-lo como sujeito portador de direitos que também participa da produção dos atos de saúde.

As reflexões sobre o processo de acolhimento remetem ao próprio sentido da palavra, aos significados que ela traz, à ideia de acolher, ouvir, receber, aproximar, estar em relação com algo ou alguém (BRASIL, 2006).

No campo da saúde o acolhimento é entendido como uma ferramenta tecnológica que compõe o modo de produzir saúde, intervindo na qualificação da escuta, construção de vínculo, garantia do acesso com responsabilização e resolutividade nos serviços. É uma tecnologia do encontro entre os atores envolvidos no processo de trabalho em saúde. Permite um olhar e uma escuta ampliada sobre as necessidades de saúde com compromisso pela busca das melhores formas de respondê-las. O MS define o acolhimento como:

[...] um modo de operar os processos de trabalho em saúde de forma a atender a todos que procuram os serviços de saúde, ouvindo seus pedidos e assumindo no serviço uma postura capaz de acolher, escutar e dar respostas mais adequadas aos usuários. Ou seja, requer prestar um atendimento com resolutividade e responsabilização, orientando, quando for o caso, o paciente e a família em relação a outros serviços de saúde para continuidade da assistência estabelecendo articulações com 
estes serviços para garantir a eficácia desses encaminhamentos (BRASIL, 2006, p. 8).

É uma ação tecnoassistencial com parâmetros éticos, técnicos, humanitários e solidários que reconhece o usuário como sujeito e participante ativo no processo de produção da saúde (BRASIL, 2006). Permite a construção de relações mais humanizadas e horizontais, em que o usuário não é visto como um objeto, mas sim como um sujeito que detém conhecimentos sobre seu processo de saúde/doença e pode/deve participar da resolução e compreensão de seu problema. Com base na responsabilização e na resolutividade, implica o trabalho conjunto e integrado de toda a rede de saúde.

Sua dimensão ética ultrapassa os limites técnico-operacionais de uma atividade programada, significando a valorização da dimensão subjetiva do ser humano, considerando-o como sujeito histórico, social e cultural. Ao mesmo tempo apresenta-se como diretriz e como estratégia. Como diretriz nos serviços de saúde representa a reorganização do trabalho, e como estratégia refere-se a uma postura diante da atenção às necessidades dos usuários. A articulação dessas perspectivas traduz os objetivos de um atendimento com garantia do acesso aos serviços e da humanização das relações estabelecidas no cotidiano das instituições (BREHMER; VERDI, 2010).

A humanização diz respeito ao resgate da dimensão humana no trabalho, ao estabelecimento de relações prazerosas, harmônicas, centradas no uso de tecnologias leves e preocupadas com a acessibilidade, resolutividade, equidade, enfim todos os princípios e diretrizes que norteiam a organização do processo de trabalho no SUS.

Esquematicamente, o processo de acolhimento pode ser definido em três etapas: inicialmente as necessidades de saúde são acolhidas em relações de diálogo e vínculo; em seguida busca-se a compreensão e significação de tais necessidades, correlacionando-as ao contexto socioeconômico, cultural e subjetivo do usuário; posteriormente busca-se a corresponsabilização entre profissionais e usuários pelas estratégias de intervenção estimulando a autonomia destes últimos na compreensão e controle de seu quadro de saúde.

Uma postura acolhedora implica o respeito e a compreensão aos conhecimentos do usuário e às diversidades, especialmente culturais (BRASIL, 2006). Significa responder às necessidades de saúde do usuário, respeitando valores, crenças e concepções deste. Isto 
só é possível por meio de uma relação dialogada e compromissada, em que o profissional tenha uma escuta atenciosa para compreender os traços culturais e a história de vida do usuário.

Para Andrade, Franco e Ferreira (2010), a compreensão das necessidades do usuário e de suas particularidades, permite reconhecê-lo como um ser singular, único e que por isso necessita ter uma resposta que também expresse essa singularidade.

O acolhimento também implica uma responsabilização que se refere a escutar a demanda do usuário, buscar a avaliação deste, identificar riscos e vulnerabilidades e, se comprometer em dar uma resposta. Essa postura permite que a assistência deixe de ser caracterizada por ações pontuais e isoladas e se multiplique em inúmeras outras ações capazes de reformular todo o processo de produção da saúde.

Solla (2005) associa a responsabilização à resolutividade, apontando que o acolhimento deve garantir o objetivo final do trabalho em saúde, que é o de responder efetivamente às necessidades do usuário. A responsabilização para com essas necessidades extrapola o atendimento propriamente dito, buscando a continuidade da atenção por meio do vínculo, da referência/ contrarreferência, do trabalho em equipe e da construção de redes de atenção ao usuário, utilizando todas as tecnologias disponíveis para tanto. Isto significa colocar o usuário de modo central na organização do processo de trabalho.

A construção dessa centralidade do usuário no processo de trabalho em saúde pressupõe as seguintes diretrizes, de acordo com Franco, Bueno e Merhy (1999): atender a todas as pessoas que procuram os serviços de saúde, garantindo acesso universal, acolhendo e buscando respostas positivas que resolvam os problemas do usuário; deslocar o eixo central do processo de trabalho do médico para uma equipe multiprofissional, em que todos os profissionais participam do processo de produção da saúde; qualificar a relação trabalhador-usuário com parâmetros humanitários, de solidariedade e cidadania.

Reorganizar o processo de trabalho de modo usuário-centrado, a partir da implantação do acolhimento, significa descentralizar a oferta do serviço de saúde das consultas médicas para as necessidades do usuário. Este entra no serviço e é acolhido de modo que todas as suas necessidades são avaliadas e o seu problema de saúde é 
contextualizado. Todos os profissionais participam da produção do cuidado e o potencial de intervenção destes aumenta consideravelmente (FRANCO; BUENO; MERHY, 1999).

Não sendo uma ação pontual e individual o acolhimento deve ocorrer durante todo o período de funcionamento do serviço de saúde. Todos os usuários que buscam o serviço devem ser acolhidos da mesma maneira. Para tanto, a implantação do acolhimento requer a aceitação da equipe de que todos acolhem e todos serão acolhidos. Para Andrade, Franco e Ferreira (2010, p. 5), "isto pode (re) significar o trabalho, representando uma relação prazerosa entre os trabalhadores e os usuários, que produz neste a sensação de ser acolhido e de direito à saúde".

Esse direcionamento possibilita a reorganização do processo de trabalho intervindo sobre as reais necessidades dos usuários. Ao mesmo tempo a implantação do acolhimento funciona como um dispositivo de indagações e mudanças, produzindo uma dinâmica nos serviços que revela as contradições da forma atual de produção do cuidado. Torna-se algo que revela os "ruídos" do processo de trabalho e permite a busca pelas "linhas de fuga".

De modo semelhante, Matumoto (1998) aponta que o acolhimento é um dispositivo de mudança na medida em que consegue instrumentalizar os trabalhadores como gestores efetivos do processo de trabalho e despertá-los para a análise de como ele está organizado. Essa análise leva à percepção das mudanças necessárias no setor saúde, efetivando a dimensão humana do trabalho em saúde e fortalecendo o SUS (MATUMOTO, 1998).

Esse entendimento rompe com a noção tradicional de acolhimento historicamente construído na área da saúde como uma dimensão espacial, que se traduz em ambiente agradável e confortável; ou como triagem administrativa e encaminhamentos para serviços especializados. Embora sejam importantes, essas ações isoladas reduzem o potencial do acolhimento não se comprometendo com os processos de construção de vínculos e responsabilizações (BRASIL, 2006).

Essa concepção restrita faz com que muitos serviços convivam com as filas que se iniciam pela madrugada; reproduzem a organização do processo de trabalho que privilegia procedimentos e atividades em detrimento dos resultados e efeitos para os sujeitos que estão sob sua responsabilidade; ofertam serviços que não correspondem às 
demandas do público atendido; não realizam avaliação de risco, identificando situações graves que necessitam de atendimento imediato (BRASIL, 2006).

É no caminho que busca superar esses entraves que a proposta de acolhimento mostra-se como um recurso importante para humanização dos serviços de saúde, na medida em que qualifica as relações, superando a noção restrita de recepção ao usuário.

É preciso não restringir o conceito de acolhimento ao problema da recepção da "demanda espontânea", tratando-o como próprio a um regime de afectabilidade (propiciador de alterações), como algo que qualifica uma relação e, portanto, passível de ser apreendido e trabalhado em todo e qualquer encontro e não apenas numa condição particular de encontro que e aquele que se da na recepção. 0 acolhimento na porta de entrada só ganha sentido se o entendemos como uma passagem para o acolhimento nos processos de produção de saúde (BRASIL, 2006, p. 6).

A noção restrita de acolhimento associa-se à ideia de triagem. Esmeraldo et al (2009) explicita a diferença entre as concepções de acolhimento e triagem. Esta última se refere a uma técnica para filtrar e organizar a demanda no serviço de saúde e utiliza apenas critérios técnicos. Na medida em que soma-se à esta ideia a apreensão da subjetividade e do contexto do usuário, por meio de uma escuta qualificada, tem-se a noção de acolhimento.

Mediante a implantação do acolhimento, o processo de trabalho é reorganizado e a recepção ao usuário ganha um novo significado,em que o principal é a escuta qualificada e a busca por uma resposta positiva que responda à necessidade do usuário. Contudo, Esmeraldo et al. (2009) apontam que nem sempre essa resposta pode ser considerada positiva pelo usuário, pois muitas vezes este vai à Unidade buscando uma resposta imediata. Como isso nem sempre é possível, muitas vezes a resposta pode ser uma orientação ou encaminhamento a outra serviço.

Mesmo que o atendimento não seja imediato, ou não seja exatamente aquilo que o usuário foi buscar, o objetivo é que este seja escutado, acolhido, e que tenha a oportunidade de compreender o porquê de tal resposta. E que tenha sua demanda respondida. A ideia de acolhimento associado à triagem muitas vezes prende-se ao número de senhas ou fichas, limitando o atendimento pela ordem de chegada na fila. $\mathrm{O}$ fim das fichas representa o fim da recepção dos usuários que buscam o serviço. 
Com o acolhimento, todos os usuários são acolhidos durante todo o dia, incidindo diretamente na acessibilidade dos usuários à Unidade. $\mathrm{O}$ acesso também se refere ao modo como o serviço está organizado o que pode burocratizar ou facilita-lo (CAVALCANTE FILHO, 2009).

O acolhimento é processo dinâmico, inacabado, em construção e nunca estará totalmente pronto. Por isso é fundamental um processo de avaliação e reorientação permanente. Enquanto processo não se restringe ao espaço físico do setor de recepção da Unidade, como também não é responsabilidade exclusiva de quem trabalha na recepção. Na verdade, o acolhimento diz respeito a toda situação de atendimento a partir do momento em que o usuário entra no sistema. Deve ser executado por todos os trabalhadores tanto em ações individuais quanto coletivas (MATUMOTO, 1998).

Nessa compreensão, o acolhimento implica: protagonismo dos sujeitos envolvidos no processo de trabalho; valorização e abertura para o encontro profissional de saúde, usuário e sua rede social; reorganização do serviço de saúde a partir da problematização dos processos de trabalho; elaboração de projeto terapêutico individual e coletivo; mudanças estruturais na forma de gestão do serviço de saúde, ampliando os espaços democráticos e de decisões coletivas; postura de escuta e compromisso em dar respostas às necessidades de saúde trazidas pelo usuário que inclua sua cultura, saberes; capacidade de avaliar riscos físicos e psíquicos; construção coletiva de propostas com a equipe local e com a rede de serviços e gerências centrais (BRASIL, 2006).

Matumoto (1998) salienta que no processo de acolhimento é fundamental questionar "qual é o problema" que será tomado como objeto no trabalho em saúde e qual a forma como ele se apresenta: pode ser o motivo pelo qual o usuário procurou o serviço de saúde, a interpretação que o profissional faz dessa necessidade do usuário ou o "problema" eleito pela instituição a partir do qual as ações de saúde são planejadas e organizadas.

Essa diferenciação é fundamental, pois ela revela a direção que será dada às práticas de saúde e acolhimento que podem ser um fim em si mesmo ou, propulsores de autonomia de usuários e trabalhadores na busca pela qualificação das ações e garantia do direito à saúde. 
Com base nos conceitos e nas reflexões sobre acolhimento tecidas, é possível sistematizar, de acordo com Silva Junior e Mascarenhas (2004), o acolhimento em três dimensões: como postura, como técnica e como princípio de reorientação dos serviços.

Como postura, pressupõe a atitude da equipe de saúde de receber, escutar, tratar humanizadamente, construindo relações de confiança, vínculo e comprometimento com a resolução das necessidades dos usuários. O diálogo é a peça chave nessa dimensão que implica também a relação intraequipe e entre os níveis de atenção do Sistema.

Enquanto técnica, o acolhimento instrumentaliza a geração de procedimentos e ações organizadas que facilitam o atendimento e enriquecem a intervenção dos diversos profissionais envolvidos na prestação da assistência. Orienta a escuta, análise, discriminação de riscos e a busca pelas soluções dos problemas demandados. Essa dimensão apoia-se no trabalho de uma equipe multiprofissional, superando a fragmentação dos saberes e da organização do trabalho.

Em sua terceira dimensão, o acolhimento busca reformular o processo de trabalho, identificando as demandas do usuário e articulando o serviço para respondê-las. Com a organização dos serviços, o acolhimento detém um projeto institucional que deve nortear o trabalho realizado por todos os profissionais. Essa proposta de trabalho orienta desde o trabalho da equipe, até o perfil dos agentes envolvidos, as capacitações, supervisões e avaliações do trabalho.

Os autores também incorporam a ideia de acessibilidade para complementar o conceito de acolhimento. Argumentam que a acessibilidade é um conjunto de circunstâncias que viabilizam a entrada do usuário no serviço. Representa as dificuldades ou facilidades dessa entrada, estando ligada ao modo como a oferta de serviços está organizada.

Para que o acolhimento se efetive em todas as suas dimensões é necessário que seja incorporado como uma diretriz tanto pelos profissionais no plano da micropolítica do trabalho em saúde, como, também, na construção das políticas de saúde, na implantação dos sistemas municipais de saúde, viabilizando os diversos pontos de atenção e recursos tecnológicos em todos os âmbitos do SUS (SOLLA, 2005). 


\section{Algumas considerações finais}

A complexidade do trabalho desenvolvido na área da saúde remete à necessidade de um processo constante de reflexão e avaliação deste, que tenha como foco a qualificação da assistência, o atendimento às necessidades do usuário e a construção de um modelo de atenção à saúde universal, integral e resolutivo.

A existência de diferentes atores envolvidos no processo de trabalho em saúde, gestores, profissionais e usuários, demanda a organização de um trabalho integrado e horizontal em que todos os sujeitos participam, seja como produtor ou como consumidor dos serviços ofertados, da construção do sistema de saúde.

Associada à integração dos diferentes sujeitos envolvidos no ato de cuidar, a perspectiva de direito deve perpassar toda a rede de saúde, incluindo deste os processos de formulação e execução das políticas, os processos de gestão e gerência destas até o plano micro de organização do trabalho nas unidades e serviços de saúde. É nesse âmbito que se destaca a potencialidade do uso das tecnologias leves em função da autonomia relativa presente na área da saúde. Enquanto tecnologias das relações, permitem a humanização e a resolutividade da assistência ao contribuir para a construção de relações de vínculo e confiança entre usuários e profissionais.

No âmbito das tecnologias leves, o acolhimento em especial sobressai como uma diretriz essencial nos serviços de saúde capaz de contribuir para a construção de um modelo de atenção à saúde centrado no usuário. Entendido como escuta qualificada que objetiva ouvir, interpretar e buscar respostas às necessidade de saúde, apresenta amplas possibilidades para: a) estimular o trabalho em equipe, ao ter como objetivo responder às necessidade do usuário, o profissional necessariamente se vê impelido a integrar-se com os outros membros da equipe e até mesmo profissionais de outros serviços e setores; $b$ ) ampliar o acesso, ao decodificar as necessidades do usuário compreendendo-as no contexto em que se inserem, o acesso do usuário aos diversos serviços da unidade é ampliado (serviços que, muitas vezes, o próprio usuário não foi buscar, como atendimentos de outros profissionais, grupos educativos, etc), além de romper com o acesso restrito à ordem de chegada no serviço e distribuição de senhas e fichas; c) impulsionar a integralidade, articulando ações de cura, prevenção e reabilitação e considerando o usuário como um todo em seu contexto social, econômico e familiar; 
d)reorganizar o processo de trabalho, rompendo com a lógica fragmentada e curativista dos serviços de saúde.

Tendo por base esse entendimento, o acolhimento pode ser apontado como um dispositivo disparador de mudanças na organização do processo de trabalho. Ao atuar com foco no usuário e nas necessidades deste e com base no conceito ampliado de saúde, o acolhimento contribui para o fortalecimento da perspectiva de direito e para a qualificação da assistência. Os processos de avaliação dos serviços de saúde devem permanentemente buscar dispositivos e estratégias, como o acolhimento, que contribuam para a consolidação de um modelo de atenção à saúde atuante na perspectiva da saúde e não da doença.

\section{Referências}

ABRAHÃO, A. L. Bases histórico-conceituais para a compreensão do trabalho em saúde. In: FONSECA, A. F.; STAUFFER, A. de B. (Org.). O processo histórico do trabalho em saúde. Rio de Janeiro: EPSJV/Fiocruz, 2007. p. 57-96.

ANDRADE, C. S.; FRANCO, T. B.; FERREIRA, V. S. C. Acolhimento: uma experiência de pesquisa-ação na mudança do processo de trabalho em saúde. Disponível em: <http://www.nates.ufjf.br/novo/revista/v010n2.htm>. Acesso em: 27 abr. 2010.

ARTIMAM, E.; RIVERA, F. J. U. Humanização no atendimento em saúde e gestão comunicativa. In: DESLANDES, S. F. (Org.). Humanização dos cuidados em saúde: conceitos, dilemas e práticas. Rio de Janeiro: Fiocruz, 2006. p. 205-234.

AYRES, J. R. de C. M. Cuidado e humanização das práticas de saúde. In: DESLANDES, S. F. (Org.). Humanização dos cuidados em saúde: conceitos, dilemas e práticas. Rio de Janeiro: Fiocruz, 2006. p. 49-84.

BRASIL. Ministério da Saúde. Secretaria Executiva. Núcleo Técnico da Política Nacional de Humanização. Acolhimento com avaliação e classificação de risco: um paradigma éticoestético no fazer em saúde. Brasília, 2004.

Ministério da Saúde. Secretaria de Atenção a Saúde. Núcleo Técnico da Política Nacional de Humanização. Acolhimento nas práticas de produção de saúde. 2. ed. Brasília, 2006.

BREHMER, L. C. de F.; VERDI, M. I. M. Acolhimento na atenção básica: reflexões éticas sobre a atenção à saúde dos usuários. Disponível em: <http://www.scielo.br/scielo.php?script=sci_arttext\&pid=S1413-81232010000900032>. Acesso em: 9 ago.2010. 
CAMPOS, G. W. Subjetividade e administração de pessoal: considerações sobre modos de gerenciar o trabalho em equipes de saúde. In: MERHY, E. E.; ONOCKO, R. (Org.). Agir em saúde: um desafio para o público. São Paulo: HUCITEC; Buenos Aires: Lugar, 1997. p. 229266.

CAMPOS, C. M. S.; BATAIERO, M. O. Necessidades de saúde: uma análise da produção científica brasileira de 1990 a 2004. Interface: Comunicação, Saúde, Educação, Botucatu, v. 11, n. 23, set./dez. 2007. p. 605-618.

CAVALCANTE FILHO, J. B. et al. Acolhimento coletivo: um desafio instituinte de novas formas de produzir o cuidado. Interface: Comunicação, Saúde, Educação, Botucatu, v. 13, n. 31, p. 315-328, dez. 2009.

CECÍLIO, L. C. O. As necessidades de saúde como conceito estruturante na luta pela integralidade e equidade na atenção em saúde. In: PINHEIRO, R.; MATTOS, R. A. Os sentidos da integralidade na atenção e no cuidado à saúde. Rio de Janeiro: EDUERJ; 2001.

ESMERALDO, G. R. de O. V. et al. Análise do acolhimento na estratégia de saúde da família sob a perspectiva do usuário. Rev. APS, Juiz de Fora, v. 12, n. 2, p. 119-130, 2009.

FRANCO, T. B. As redes na micropolítica do processo de trabalho em saúde. In: PINHEIRO, R.; MATTOS, R. A. (Org.). Gestão em redes: práticas de avaliação, formação e participação na saúde. Rio de Janeiro: CEPESC, IMS/UERJ, LAPPIS, 2006. v. 1, p. 459-474

FRANCO, T. B.; MERHY, E. E. A produção imaginária da demanda e o processo de trabalho em saúde. In: PINHEIRO, R.; MATTOS, R. A. (Org.). Construção social da demanda: direito à saúde, trabalho em equipe, participação e espaços públicos. Rio de Janeiro: CEPESC/ UERJ: ABRASCO, 2005. p. 181- 194

FRANCO, T. B.; BUENO, W. S.; MERHY, E. E. O acolhimento e os processos de trabalho em saúde: o caso de Betim (MG). Caderno de Saúde Pública, Rio de Janeiro, v. 15, n. 2, p. 345353, abr./jun. 1999.

FRIEDRICH, D. B. de C. O trabalho em saúde: focalizando pessoas e processos nas equipes de saúde da família em Juiz de Fora. 2005. Tese (Doutorado em Saúde Coletiva) UERJ/IMS, Rio de Janeiro, 2005.

LIMA, J. C. F. Bases histórico-conceituais para a compreensão do trabalho em saúde. In: FONSECA, A. F.; STAUFFER, A. de B. (Org.). O processo histórico do trabalho em saúde. Rio de Janeiro: EPSJV/Fiocruz, 2007. p. 57-96.

MATUMOTO, S. O acolhimento: um estudo sobre seus componentes e sua produção em uma unidade da rede básica de serviços de saúde. 1998. Dissertação (Mestrado em Enfermagem) - Escola de Enfermagem de Ribeirão Preto/ USP, Ribeirão Preto, 1998.

MERHY, E. E. Em busca do tempo perdido: a micropolítica do trabalho vivo em saúde. In: MERHY, E. E.; ONOCKO, R. (Org.). Agir em saúde: um desafio para o público. São Paulo: Hucitec, 1997. p. $71-113$. 
Saúde: a cartografia do trabalho vivo. São Paulo: HUCITEC, 2002.

PEDUZZI, M. Mudanças tecnológicas e seu impacto no processo de trabalho em saúde. Trabalho, Educação e Saúde, Rio de Janeiro, v. 1, n. 1, p. 75-91, 2003. Disponível em: <http://www.epsjv.fiocruz.br/beb/periodicos/mudancastecnologicasv1n12003>. Acesso em: 7 jun. 2008.

PIERANTONI, C. R. As reformas do Estado, da saúde e recursos humanos: limites e possibilidades. Rev. Ciência e Saúde Coletiva, Rio de Janeiro, v. 6, n. 2, p. 341-360, 2001.

RAMOS, M. N. Conceitos básicos sobre trabalho. In: FONSECA, A. F.; STAUFFER, A. de B. (Org.). O processo histórico do trabalho em saúde. Rio de Janeiro: EPSJV/Fiocruz, 2007. p. 27-56.

RIBEIRO, E. M.; PIRES, D.; BLANK, V. L. A teorização sobre processo de trabalho em saúde como instrumental para análise do trabalho no Programa Saúde da Família. Caderno de Saúde Pública, Rio de Janeiro, v. 20, n. 2, 2004.

SILVA JUNIOR, A. G.; MASCARENHAS, M. T. M. Avaliação da atenção básica em saúde sob a ótica da integralidade: aspectos conceituais e metodológicos. In: PINHEIRO, R.; MATTOS, R. A. (Org.). Cuidado as fronteiras da integralidade. Rio de Janeiro: Hucitec/ABRASCO, 2004. p. 241 - 257.

SILVA JUNIOR, A. G. et al. Entre tramas e redes: cuidado e integralidade. In: PINHEIRO, R.; MATTOS, R. A. (Org.). Construção social da demanda: direito à saúde, trabalho em equipe, participação e espaços públicos. Rio de Janeiro: CEPESC/UERJ: ABRASCO, 2005. p. 77-89.

SCHRAIBER, L. B. et al. Planejamento, gestão e avaliação em saúde: identificando problemas. Revista Ciência e Saúde Coletiva, Rio de Janeiro, v. 4, n. 2, p. 221-241, 1999.

SOLLA, J. J. S. P. Acolhimento no sistema municipal de saúde. Rev. Bras. Saúde Matern. Infant., Recife, v. 5, n. 4, p. 493-503, out./dez. 2005.

STOTZ, E. N. Os desafios para o SUS e a educação popular: uma análise baseada na dialética da satisfação das necessidades de saúde. 2003. Disponível em: <http://www.redepopsaude.com.br/varal/ politicasaude/desafiosus.htm>. Acesso em: 7 jun. 2008.

TRAD, L. A. B. Humanização do encontro com o usuário no contexto da Atenção Básica. In: DESLANDES, S. F. (Org.). Humanização dos cuidados em saúde: conceitos, dilemas e práticas. Rio de Janeiro: Fiocruz, 2006, p.185- 203. 